\title{
THE IMPACT OF PUBLIC HEALTH EXPENDITURE ON ECONOMIC DEVELOPMENT - EVIDENCE FROM PREFECTURE-LEVEL PANEL DATA OF SHANDONG PROVINCE
}

\author{
Lin $\mathrm{Li}$
}

SHU-UTS SILC Business School, Shanghai University, P.R.China

\author{
Maoguo $\mathrm{Wu}^{*}$ \\ SHU-UTS SILC Business School, Shanghai University, P.R.China \\ Zhenyu Wu \\ SHU-UTS SILC Business School, Shanghai University, P.R.China
}

\begin{abstract}
Public health expenditure is an indispensable part of social economy. The public has always paid close attention to public health expenditure. In order to study the quantitative relation between public health expenditure and social economic development, this paper investigates prefecture-level cities in Shandong Province, due to the unique characteristics of Shandong Province. Making theoretical and empirical contribution, this paper augments Cobb-Douglas production function with public health expenditure and empirically analyzes economic development of prefecture- level cities in Shandong Province. A panel data set is set up, followed by multivariate regression analysis. Empirical results find that public health expenditure per capita and coverage of medical insurance can significantly promote the development of social economy. At the same time, expansion of the scale of health institutions and growth of the number of health institutions cannot promote economic development. Instead, it may even hold back economic development by causing personnel redundancy and waste of resources. If the government transfers its investment focus from the scale and the speed of development of medical services to the fairness and the efficiency of medical services, public health expenditure may bring greater benefits to the improvement of both social public health condition and economic development.
\end{abstract}

Keywords: Public Health Expenditure, Economic Development, Panel Data, Shandong

JEL code: C33, I18

\section{Introduction}

In recent years, public health expenditure has become a topic with intense public concern. By the progress of public health such as the reform of the medical and health system and the improving relationship between doctors and patients in several metropolises in China such as Beijing, Shanghai, Ningbo, and Chengdu, it has raised the health level of the people in those regions and become a powerful driving force for economic development. Nowadays, Beijing, Shanghai, Ningbo, and Chengdu have become the new centers of medical resources. A new round of economic growth broke 
out in the areas which are rich in medical resources, forming a new economic centers then. As an important factor that affects regional economic development, the study of the relationship between public health expenditure and regional economic growth also appears more and more important and quantitative research on the relationship also has huge economic and social values.

Since 2007, Shandong Province's GDP has been overtaken by Jiangsu province, ranking third in China. According to statistics, the total amount of public health expenditure in Shandong has always been higher than that in Jiangsu. However, because of its large population, the average public health expenditure of Shandong is much lower than that of Jiangsu. Although the Shandong provincial government pays attention to public health expenditure, there are still notable problems in the actual situation, and it is obvious that there are some hidden dangers in the public health. As the research object, the characteristics of Shandong such as its high living standards, strong comprehensive strength, unbalanced medical resources distribution and economic development in city levels makes itself special and representative. Therefore, based on the provincial panel data of Shandong, this paper will compare and analyses the data obtained, and investigates the impact of the regional public health expenditure on economic development. Based on the empirical results and the local situation, this paper provides policy implications for the local economic and public health development strategy, so as to better achieve the development goals.

The remaining part of this paper is organized as follows. Section 2 reviews related literature. Section 3 introduces the theoretical model. Section 4 is devoted to empirical analysis. Section 5 is causality analysis. Section 6 concludes the paper and proposes policy implications.

\section{Related Literature}

Health economics is a relatively new branch of the research on economic development. A great deal of research pertains to the impact of health on economic development. Mayer et al. (2008) and Muysken (2008) argue that health has a positive effect on economic growth, where healthy life is the prerequisite of an effective labor, and, by measuring the roles of various factors in promoting economic growth, they conclude that health factors contribute more than the education factors to improve the efficiency of workers. Based on Granger Test for panel data of 16 major India cities, Mohapatra \& Mishra (2011) states that the growth of Gross State Domestic Product causes increase in Health Expenditure in both long run and short run, but Health Expenditure only has effect on Gross State Domestic Product in the long run. Balaji (2011) reaches similar conclusion with the same methodology specifically based on the four Southern Indian states. Whereas, based on data from different countries classified by Human Development Index (HDI), Mohammad \& Fatemeh (2015) points out that health expenditure only has positive effect on countries with very high HDI. And Eggoh. et al (2015) confirmed the conclusion by quantitative analysis of 49 African countries, stating that public health expenditure has negative effect on economic growth of less developed African countries; by contrast, Sussex et al. (2016) points out that the government and private funds for medical research and development has statistically 
significant positive effect on the national economic development. For China, analysis nationwide time series within a multivariate Beveridge-Nelson decomposition framework in both permanent and cyclical variables. Chen et al. (2013) argues that public health expenditure has pro-cyclical correlation with GDP growth. Meanwhile, analysis provincial-level panel data also find the same result, which indicates that public health expenditure can contribute to the economic development. Fan (2012) and Xu (2012) conclude that health economic research in China mainly has three aspects: health demand model, the efficiency and fairness problems led by health, and medical reform medical in China. Wang (2008), using the Arrow-Romer production function and Grossman human capital requirement model, finds that there is a positive correlation between economic growth and health expenditure in the short term, but in the long term it is suppressed because of the excessive growth of the expenditure.

Research on economic growth based on Cobb-Douglas function in China is mainly focuses on labor force, education and technology. In terms of population, based on panel data of six provinces (cities) in Northern China within Cobb-Douglas production function, Zhao (2016) depicts that there exists bidirectional causal relation between labor force and GDP growth in four of the sample regions. Guo (2011), by extending the Cobb-Douglas function, establishes the human capital externalities model with data of material capital, human capital and the growth level of human capital of 1984-2008 in Henan province, which measures their contribution rate to economic growth. Ge (2015) extends the Cobb-Douglas function by adding the bringing up ratio and the number of the educational years. It estimates and explores the influence that the human capital and population bonus have on economic growth nationwide and in Shanghai between 1978 and 2012. In terms of education, a large number of papers use the CobbDouglas function to study on the relationship between fiscal expenditure on education and the economic growth, for examples, Cao (2012) found that fiscal expenditure on education of multi-nationality has great contribution to economic growth. Fu et al. (2012) use Denison-Madison algorithm to analyze the effects that higher education investment has on economic growth during 1994 and 2008 in Liaoning Province, and finds out that the influence is strengthening but still at a relatively low level in China. Gao (2013) takes GDP, capital stock and the number of graduates in 1995-2010 as samples, and measures the contribution to the economic growth of adult higher education and the regular higher education in Yunnan Province. It concludes that the adult higher education in Yunnan province has low economic contribution rate, which only accounts for $40 \%$ of the ordinary higher education. In terms of science and technology. Bhorat et al. also argues that further education and training (FET), such as vocational training, other than formal tertiary degree education does not significantly contribute to economic growth in South Africa, which is similar to the finding of Gao (2013). Sun and Jiang (2014) take the amount of the activities that scientists participate in as the key explanatory, to explore influence of scientific personnel input on Midwest regional economic growth in China. Yang (2015) establishes an endogenous model based on the data of 1999-2013, and conducts analysis of the interaction mechanism between technological progress, financial development and economic growth of Sichuan and Chongqing. In the field of health economics, few theoretical studies have 
been conducted on this model, which is also the innovation of this paper. Similarly, based on empirical analysis of 219 Taiwan electronic manufacturers, Scholar Liu (2008) finds that both internal R\&D inputs and externality imported technologies positively contribute to the designs and sales of high value added products in Taiwan's electronic industry from 1990-2003. Whereas, there are very few theoretical studies based on this model. This paper attempts to fill in gaps in previous research mentioned above and contributes to exiting literature on health economics.

\section{Theoretical Model}

This paper is based on CES (Constant Elasticity of Substitution production function). It only considers capital, labor and technology in the production function, and the equation is as, and the expression is as follows:

$$
\mathrm{Y}=\mathrm{A}\left(\delta_{1} K^{-\rho}+\delta_{2} \mathrm{~L}^{-\rho}\right)^{1 / \rho}, \mathrm{K}>\text { and } \mathrm{L}>0,
$$

where $\rho$ is infinitely approximating 0 , the Cobb-Douglas production function, can be deduced, expression is as follows:

$$
Y_{0}=A_{0} K^{\alpha} L^{\beta} \mu
$$

where, Y0 is total output, A0 is comprehensive technical level, $\mathrm{K} \alpha$ is capital input, $\mathrm{L} \beta$ is labor input, $\alpha$ is the output elasticity of capital, $\beta$ is the output elasticity of labour, $\alpha>0, \beta>0, \mu$ is a random error.

In combination with the previous literature, it can be found that the model above can be extended, not only A, which is on behalf of the input of science and technology, has significant economic and statistical contribution to the improvement of the social and economic output of Y; The public health input which can guarantee the high efficiency of labor in the production of social materials, also has significant contribution to economic output. Thus, this paper extends the linear model. In addition to the A0, the comprehensive technical level, introduces a comprehensive public health input related coefficient of $\mathrm{H} 0$ (Health).

The extended function is of the following form:

$$
Y_{0}=\mathrm{A}_{0} \mathrm{H}_{0} K^{\alpha} L^{\beta} \mu
$$

where, $\mathrm{Y} 0$ is total output, $\mathrm{A} 0$ is comprehensive technical level, $\mathrm{H} 0$ is comprehensive public health input, $\mathrm{K} \alpha$ is capital input, $\mathrm{L} \beta$ is labour input, $\alpha$ is the output elasticity of capital, $\beta$ is the output elasticity of labour, $\alpha>0, \beta>0$, $\mu$ is random error.

This paper takes the social total output "GDP" as the explained variable, and the social fixed capital, as the main explanatory variables, which are represented by "Y" and "K", respectively. A0, which indicates comprehensive technical level, is subdivided into A1 which directly reflects the per capita input of scientific research funds, and A2, the proportion of bachelor or higher degree holders among middle school teachers. At the same time, $\mathrm{H}$ is also subdivided into $\mathrm{H} 1$, the amount of per capita medical practitioners (practicing physicians and nurses), and $\mathrm{H} 2$, the average number of medical practitioners (practicing physicians and nurses) in the hospitals (excluding towns and townships), and $\mathrm{H} 3$, the per capita amount of hospital (excluding towns and townships), and $\mathrm{H} 4$, the percentage of people who get medical insurance. 
After adding all variables, the model is:

$$
Y=A_{1} A_{2} H_{1} H_{2} H_{3} \mathrm{H}_{4} K^{\alpha} L^{\beta} \mu
$$

According to the combination of $\alpha$ and $\beta$, there are three possible scenarios:

when $\alpha+\beta>1$, it is advantageous to increase the scale of production by using existing technical level;

when $\alpha+\beta<1$, it is not worth to expand the production scale with existing technology level;

when $\alpha+\beta=1$, the production efficiency does increase with the existing production scale. It gets more economic benefits only with the improvement of existing technical level.

In this paper, a regression estimation method is used to determine the contribution rate of public health input to output growth. This method assumes that the scale of compensation is constant, i.e. $\alpha+\beta=1$. Then take logarithm of both sides:

$$
\ln Y=\ln A_{1}+\ln A_{2}+\ln H_{1}+\ln H_{2}+\ln H_{3}+\ln H_{4}+\alpha \ln K+\beta \ln L
$$

It is modified into

$$
\ln A_{1}+\ln A_{2}+\ln H_{1}+\ln H_{2}+\ln H_{3}+\ln H_{4}+\alpha \ln K+(1-\alpha) \ln L
$$

Manipulating equation 6 yields

$$
\ln Y-\ln L=\ln A_{1}+\ln A_{2}+\ln H_{1}+\ln H_{2}+\ln H_{3}+\ln H_{4}+\alpha(\ln K-\ln L)
$$

Finally, the simple linear regression model can be obtained:

$$
\begin{aligned}
& \ln \frac{Y}{L}=\ln A_{1}+\ln A_{2}+\ln H_{1}+\ln H_{2}+\ln H_{3}+\ln H_{4}+\alpha \ln \frac{K}{L} \\
& \ln y=\ln A_{1}+\ln A_{2}+\ln H_{1}+\ln H_{2}+\ln H_{3}+\ln H_{4}+\alpha \ln k
\end{aligned}
$$

The explained variable $\mathrm{y}$ is the output value per capita (GDP per capita), and $\mathrm{k}$ is the fixed capital investment per capita; $\alpha$ is the coefficient and determine the public health on output per person, on the basis of determination of the contribution rates of science and technology progress, labor and capital growth inputs.

The function after regression is:

$$
\underset{\alpha \ln k}{\ln y}=c_{0}+c_{1} \widehat{\ln A_{1}}+c_{2} \widehat{\ln A_{2}}+c_{3} \widehat{\ln H_{1}}+c_{4} \widehat{\ln H_{2}}+c_{5} \widehat{\ln H_{3}}+c_{6} \widehat{\ln H_{4}}+
$$

In this model, $\mathrm{c}_{0}$ is the intercept, $\mathrm{c}_{1}-\mathrm{c}_{6}$ are the coefficients to be estimated, $\alpha$ is the elasticity of capital inputs.

\section{Empirical Analysis}

The data of this paper are gathered from the "The Yearbook of Shandong Province", which contains relevant data of 17 prefecture-level in Shandong Province from 20002015 "GDP", "Gross Social Fixed Asset Investment", "Government R\&D Expenditure","Total Number of High School Teachers", "The Number of Middle School Teachers with Bachelor's Degree or Above", "Medical practitioners (Chartered physicians and nurses) Number", Number of Hospitals (not including rural clinics), 
"Number of Population Covered by Medical Insurance", as well as "Total Population". The panel is established, based on the data above.

After data cleaning and processing, GDP per capita is calculated preliminarily as the explained variable. Meanwhile, relevant explanatory variables-Government R\&D Expenditure per Capita " $\mathrm{A}_{1}$ ", The Percentage of High School Teachers with Bachelor Degree or Above " $\mathrm{A}_{2}$ ", Medical practitioners (Chartered physicians and nurses) Number per Capita " $\mathrm{H}_{1}$ ", Number of Medical practitioners (Chartered physicians and nurses) per Hospital (excluding towns and townships) " $\mathrm{H}_{2}$ ", Number of Hospital (excluding towns and townships) per Capita " $\mathrm{H}_{3}$ ", Percentage of the Population covered by Medical Insurance " $\mathrm{H}_{4}$ ", and Social Fixed Asset Investment per Capita " $\mathrm{k}$ ". According to the modified Cobb-Douglas production function, the explained variables and explanatory variables above are taken natural logarithm, respectively.

In order to avoid the case of "spurious regression" caused by the time trend of variables, it is imperative to carry out the "Unit Root Test" on the variables, to confirm the stationarity of variables the panel data.

The unit root test of panel is usually tested by the Levin-Lin-Chu unit - root test (LLC) or Fisher-ADF unit-root test, where the LLC properly applies to the "Same Root" situation, and the Fisher -ADF is usually applied to the situation of "Different Root"; In the case of lacking prejudgement, only if both tests reject the null hypothesis-all panels contain the roots, can the sequence be deemed as stationary.

After an initial unit root test, it is found that the dependent variable, as well as the explanatory variables do not contain time trends under both of the two Unit Root tests, which means that both variables are stationary without time trend; while the rest of the explanatory variables are stationary only in the presence of time trend; thereafter, the processing of eliminating time trends of those variables is taken, and the units root test for the no time-trend variables can be taken then

\section{Fisher unit-root test}

$\mathrm{H}_{0}$ : All panels contain unit roots

$\mathrm{H}_{1}$ : At least one panel is stationary

\begin{tabular}{|c|c|c|c|}
\hline $\begin{array}{c}\text { Statistics } \\
\text { Variables }\end{array}$ & $\begin{array}{c}\text { Inverse chi- } \\
\text { squared }\end{array}$ & $\mathrm{p}$-value & $5 \%$ reject $\mathrm{H} 0 ?$ \\
\hline $\ln y$ & 76.3518 & 0.0000 & Yes \\
\hline $\ln k_{d t}$ & 156.7431 & 0.0000 & Yes \\
\hline $\ln A_{1 d t}$ & 55.5804 & 0.01122 & Yes \\
\hline $\ln A_{2}$ & 298.7278 & 0.0000 & Yes \\
\hline $\ln H_{1 d t}$ & 70.3897 & 0.0000 & Yes \\
\hline $\ln H_{2}$ & 86.7694 & 0.0000 & Yes \\
\hline $\ln H_{3}$ & 135.6523 & 0.0000 & Yes \\
\hline $\ln H_{4 d t}$ & 60.5534 & 0.0034 & Yes \\
\hline
\end{tabular}

Reject the null hypothesis, at least one panel is stationary

\section{Levin-Lin-Chu unit-root test}

$\mathrm{H}_{0}$ : All panels contain unit roots 
$\mathrm{H}_{1}$ : At least one panel is stationary

\begin{tabular}{|c|c|c|c|}
\hline $\begin{array}{c}\text { Statistics } \\
\text { Variables }\end{array}$ & Adjusted ${ }^{*}$ & p-value & $5 \%$ reject H0? \\
\hline $\ln y$ & -10.8559 & 0.0000 & Yes \\
\hline $\ln k_{d t}$ & -10.6030 & 0.0000 & Yes \\
\hline $\ln A_{1 d t}$ & -2.2815 & 0.0113 & Yes \\
\hline $\ln A_{2}$ & -15.0005 & 0.0000 & Yes \\
\hline $\ln H_{1 d t}$ & -4.7959 & 0.0000 & Yes \\
\hline $\ln H_{2}$ & -3.2304 & 0.0006 & Yes \\
\hline $\ln H_{3}$ & -4.6751 & 0.0000 & Yes \\
\hline $\ln H_{4 d t}$ & -6.1478 & 0.0000 & Yes \\
\hline
\end{tabular}

Reject the null hypothesis, at least one panel is stationary, both Levin-Lin-Chu unitroot test and Fisher-ADF unit-root test reject the null hypothesis at 95\% confidence level, which shows that all of the time series are stationary.

For the panel data estimation methods, there are several kinds of main forms: Ordinary Least Squares (OLS), Generalized Least Squares (GLS), Pooled OLS/WLS, Fixed Effect Model, and Random Effect Model. The choice of the most suitable estimation methods requires proper parametric tests or non-parametric tests, such as Breusch and Pagan LM test for companing OLS or random effect, Hausman test for the Random Effect and Fixed Effect Models judgment, as well as determining whether take the generalized least squares (GLS), pooled OLS/WLS based on the Modified Wald test for groupwide heteroskedasticity and Pesaran's/Friedman's cross-section correlation tests, etc.

Breusch and Pagan LM Test for Ordinary Least Squares (OLS) or Random Effect Model selection

$\mathrm{H}_{0}$ : $\operatorname{Var}(\mathrm{u})=0$

$\mathrm{H}_{1}: \operatorname{Var}(\mathrm{u}) \neq 0$

\begin{tabular}{|c|c|}
\hline chibar(01) & $=247.55$ \\
\hline P-value & 0.0000 \\
\hline
\end{tabular}

Reject the null hypothesis, Random effect model should be used in favour of OLS model

\section{Hausman Test for Fixed Effect Model or Random Effect Model}

$\mathrm{H}_{0}$ : Difference in coefficients not systematic

$\mathrm{H}_{1}$ : Difference in coefficients systematic

\begin{tabular}{|cc|cc|}
\hline \multicolumn{3}{|c|}{ Hausman fixed random } \\
\hline$\chi^{\mathbf{2}(7)}$ & & $=-11.21$ \\
\hline \multicolumn{3}{|c|}{ Hausman fixed, sigmaless } \\
\hline$\chi^{\mathbf{2}(7)}$ & & & $=30.55$ \\
\hline P-value & & 0.0002 \\
\hline \multicolumn{3}{|c|}{ Hausman fixed, sigmamore } \\
\hline$\chi^{\mathbf{2}(7)}$ & & & $=27.39$ \\
\hline
\end{tabular}




\section{\begin{tabular}{l|r} 
P-value & 0.0006
\end{tabular}}

Reject the null hypothesis, difference in coefficients is systematic, fixed effect model should be used

Modified Wald test for groupwide heteroskedasticity in fixed effect regression model

$\mathrm{H}_{0} \quad \sigma(\mathrm{i})^{\wedge} 2=\sigma^{\wedge} 2$ for all $\mathrm{i}$

$\mathrm{H}_{1}$ Not all $\sigma(\mathrm{i})^{\wedge} 2=\sigma^{\wedge} 2$

\begin{tabular}{|c|c|}
\hline$\chi^{2}(17)$ & $=114.08$ \\
\hline $\mathrm{P}>\chi^{2}$ & $=0.0000$ \\
\hline
\end{tabular}

Reject the null hypothesis, there is groupwide heteroskedasticity

Pesaran's test of cross sectional independence

$\mathrm{H}_{0}$ Cross sectional independence

$\mathrm{H}_{1}$ : Cross sectional not independence

\begin{tabular}{|c|c|}
\hline$\chi^{2}$ & 33.833 \\
\hline $\operatorname{Pr}$ & 0.0000 \\
\hline
\end{tabular}

Friedman's test of cross-sectional independence

$\mathrm{H}_{0}$ Cross sectional independence

$\mathrm{H}_{1}$ : Cross sectional not independence

\begin{tabular}{|c|c|}
\hline$\chi^{2}$ & 150.584 \\
\hline P-value & 0.0000 \\
\hline
\end{tabular}

Reject the null hypothesis, there is no Cross-sectional dependence in the panel

\section{Robustness Check}

Based on the tests above, there exists heteroscedasticity and cross-section correlation in the panel data, a Robust Checklist is demanded to choose fitted models among Generalized Least Squares GLS with heteroscedasticity and cross section correlation correction (GLS,correlated), Pooled OLS under Fixed Effect (Scc,FE) or Fixed Effects model with heteroskedasticity correction (FE,Robust).

Robust Checklist:

\begin{tabular}{|c|c|c|c|}
\hline $\begin{array}{l}\text { Explanatory } \\
\text { variables }\end{array}$ & $\begin{array}{c}\text { GLS,Correlate } \\
\mathrm{d}\end{array}$ & Scc,FE & FE,Robust \\
\hline $\ln y$ & $\begin{array}{c}.2706012 \\
(.0052754) \\
* * *\end{array}$ & $\begin{array}{c}.1118398 \\
(.0447841)\end{array}$ & $\begin{array}{c}.1118398 \\
(.0815373)\end{array}$ \\
\hline & -.1419791 & -.1414873 & -.1414873 \\
$\ln k_{d t}$ & $(.0061037)$ & $(.0431344)$ & $(.0806738)$ \\
& $* * *$ & $* * *$ & $*$ \\
\hline & 6.101361 & 5.44467 & 5.44467 \\
$\ln A_{1 d t}$ & $(.065666)$ & $(.2521266)$ & $(.3746913)$ \\
& $* * *$ & $* * *$ & .5026396 \\
\hline $\ln A_{2}$ & .4887737 & .5026396 & $(.1819829)$ \\
\hline
\end{tabular}




\begin{tabular}{|c|c|c|c|}
\hline & $* * *$ & $* * *$ & $* *$ \\
\hline $\ln H_{1 d t}$ & $\begin{array}{c}. .293131 \\
(.0067281) \\
* * *\end{array}$ & $\begin{array}{c}-.3301896 \\
(.1087158) \\
* *\end{array}$ & $\begin{array}{c}-.3301896 \\
(.1812852) \\
*\end{array}$ \\
\hline $\ln H_{2}$ & $\begin{array}{c}-.0619485 \\
(.0034985) \\
* * *\end{array}$ & $\begin{array}{c}-.0398739 \\
(.0390786)\end{array}$ & $\begin{array}{c}-.0398739 \\
(.0199207) \\
*\end{array}$ \\
\hline $\ln \mathrm{H}_{3}$ & $\begin{array}{c}.1378829 \\
(.0058969) \\
* * *\end{array}$ & $\begin{array}{c}.1150052 \\
(.0515118) \\
* *\end{array}$ & $\begin{array}{l}.1150052 \\
(.0779126)\end{array}$ \\
\hline $\ln H_{4 d t}$ & $\begin{array}{c}.1378829 \\
(.0058969) \\
* * *\end{array}$ & $\begin{array}{l}.1150052 \\
(.0515118) \\
* *\end{array}$ & $\begin{array}{l}.1150052 \\
(.0779126)\end{array}$ \\
\hline $\mathrm{c}$ & $\begin{array}{c}12.24845 \\
(.0493908) \\
* * *\end{array}$ & $\begin{array}{c}12.48496 \\
(.5750891) \\
* * *\end{array}$ & $\begin{array}{c}12.48496 \\
(.9746479) \\
* * *\end{array}$ \\
\hline R-Squar & N/A & 0.8624 & within $=0.8624$ \\
\hline
\end{tabular}

According to the statistical significance of each explanatory variable coefficient, Generalized Least Squares Model with heteroskedasticity and cross section correlation correction (GLS,correlated) model should be applied for regression analysis.

The regression result:

$$
\begin{aligned}
& \widehat{\operatorname{lny}} \quad=12.24845+0.2706012 \\
& 0.1419791 \widehat{\operatorname{lnA_{1dt}}}+6.101361 \widehat{\ln }_{2}+0.4887737 \widehat{\operatorname{lnH}}_{1 d t} \\
& \text { (.0493908) (.0052754) (.0061037) (.065666) } \\
& -0.293131 \widehat{\operatorname{lnH}_{2}}-0.0619485 \ln _{3}+0.1378829 \sqrt{\ln H_{4} d t} \\
& \begin{array}{lll}
(.0067281) & (.0034985) \quad(.0058969)
\end{array} \\
& \widehat{\operatorname{lnk}}_{d t}- \\
& (.0211006)
\end{aligned}
$$

\section{Regression result analysis :}

All the coefficients of the explanatory variables includingaand $\mathrm{c}_{1}-\mathrm{c}_{6}$ are statistically significant at $99 \%$ confidence level, which indicates that variables have a strong explanatory effect on the dependent variable. The regression verifies that in addition to the factors--Gross Social Fixed Asset Investment, Science \& Technology-in precedent studies that, the new factor -- social and public health investmentintroduced in this paper is also a significant effect on social and economic development.

Among them, the coefficients of Social Fixed Asset Investment per Capita "k", The Percentage of High School Teachers with Bachelor's Degree or Above "A2", Medical practitioners (Chartered physicians and nurses) Number per Capita " $\mathrm{H}_{1}$ ", The Percentage of Population covered by Medical Insurance "H4" are positive; whereas, these variables have significantly positive impact on GDP per capita "Y". Among the public health expenditure variables - the Medical Practitioners (Chartered physicians and nurses) Number per Capita " $\mathrm{H}_{1}$ ", The Percentage of Population covered by Medical Insurance " $\mathrm{H}_{4}$ ", have an elasticity of $48.9 \%$ and $13.8 \%$, respectively, which indicates that the abundance of medical resources per capita, the improvement of health insurance coverage can significantly promote the development of social economy. This result 
complies with the focus of "New Medicare Reform" in China.

Meanwhile, other explanatory variables--Government R\&D Expenditure per Capita " $A_{1}$ ", the Number of Medical practitioners (Charted physicians and nurses) per Hospital (excluding towns and townships) " $\mathrm{H}_{2}$ ", the Number of Hospital, (excluding towns and townships) per Capita " $\mathrm{H}_{3}$ " - have significant negative effect on GDP per capita "Y". Among which, variables related to public health-- the Number Medical practitioners (Chartered physicians and nurses) per Hospital (excluding towns and townships) " $\mathrm{H}_{2}$ " has a negative elasticity as high as $29.3 \%$, which shows that the increasing number and scale expansion of the health agencies may not be able to promote economic development, by contrast, the redundancy of personnel and resource waste may instead become an obstacle of economic development. This is also a key issue in the reform of the "Supply Side" on how to achieve the best match between supply and demand to solve the problems in public health area.

\section{Causality Analysis}

Taking into account of the previous research and related social economics research, the causes of the negative correlation between may be as follows: first of all, scientific research expenditure is not entirely used for research, or for some ineffective and even invalid scientific research projects. They may not produce material and spiritual products to promote the development of social economy. Instead, they lead to "crowding out" effects and cause unreasonable resource allocation, which hinders economic development. Regarding to the difficulties that the number of average hospital medical practitioners brings to the economy, the reason may be that hospital administrative jobs are bloated, and government health expenditures are greatly wasted, and the special fund is difficult to be totally spent on research and development. The reason why per capita number of hospitals has negative correlation with economic growth is that some government officers only pursuit political achievements, and the expenditures are only financing less relevant projects. In the long term, it will hinder the economic development.

\section{Conclusion and Recommendations}

To achieve effective public health input, the basic way is to solve problems of public health in the pursuit of efficiency and fairness. The aim is to satisfy the public needs of health and equitably distribute limited sources.

For a long time, Shandong is influenced by the traditional concepts of GDP development, and some officials simply regard solid development as GDP growth. In the field of public health, they also aim at expanding the scale of medical services, and mistakenly regard medical service efficiency as the speed of medical service development, development scale, the scope of services and the quantity of service. Additionally, the unseasonable evaluation system makes officials pay attention to the political performance, rather than the fairness and effectiveness. With such a short-term sight, in the long run, even if the public health investment is growing, it cannot really improve the conditions of social and public health and even hinder social development. Thus, this paper argues that when the government make decision about public health 
development, it should not just consider whether there are rich medical resources or advanced technology, or large infrastructure scale, instead, it should focus on fair, reasonable and effective public health resources allocation, and utilize limited resources to satisfy the public health needs as far as possible, and try to narrow the gap of public health resource allocation among the cities. Although this cannot be perfectly achieved, through making laws and regulations for public health input, and improving the evaluation system, government can achieve the rational allocation of public health investment, and maximize its utility, therefore, improve residents' health level, and guarantee that workers are complying on the social production effectively and efficiently, continuously promoting economic development.

\section{References}

Balaji, B. (2011) "Causal Nexus Between Public Health Expenditure and Economic Growth in Four Southern Indian States", IUP Journal of Public Finance, vol. 9, no. 3, pp.7-22.

Bhorat, H., Cassim, A. and Tseng, D. (2016), "Higher education, employment and economic growth: Exploring the interactions", Development Southern Africa, vol. 33, no. 3, pp. 312-327.

Jiang, B. (2012) "Empirical research on the demographic dividend and economic growth 1980 of the Pearl River delta" (In Chinese), South China University of Technology.

Breusch, T. S. and Pagan, A. R. "The Lagrange multiplier test and its applications to model specification in econometrics". Review of Economic Studies, vol.47, pp. 239-253. Cao, F. (2012) "Research on the relationship between the expenditure of fiscal education and economic growth in ethnic areas" (In Chinese), Inner Mongolia University.

Chen, G., Inder, B., Lorgelly, P and Hollingsworth, B. (2013) “The cyclical behavior of public and private health expenditure in China", Health Economics [Health Econ], vol. 22 (9), pp. 1071-92.

Dong, X. H., Wang Xin, and Li, C. (2008) "Cobb - Douglas production function theory research review” (In Chinese), Productivity Research (3), pp. 148-150.

Driscoll, J. C. and Aart, C. K. (1998) "Consistent Covariance Matrix Estimation with Spatially Dependent Panel Data”, Review of Economics and Statistics, vol. 80, pp. 549560.

Eggoh, J., Houenivo, H. and Sossou, G. A. (2015) "Education, Health and Economic Growth in Africa Countries", Journal of Economic Development. vol. 40, no. 1, pp. 93 111. 
Friedman, M. "The use of ranks to avoid the assumption of normality implicit in the analysis of variance", Journal of the American Statistical Association. pp. 675-701.

Fu, S.Y., Sun, S., J. Xing, H. (2012) "Based on c-d function of higher education to regional economic growth contribution rate research - in Liaoning province as an example" (In Chinese), Journal of Shenyang university of technology (social science edition), vol. 5(2), pp.132-136.

Ge, Y. (2015) "From demographic dividend to human capital dividend (In Chinese)", Shanghai academy of social sciences.

Greene, W. (2000) Econometric Analysis, New York: Prentice-Hall.

Guo S. L. (2011) "Empirical research on human capital and economic growth in Henan province" (In Chinese), Jinan University.

Guo, Z. Y. (2015) "Profit distribution research for China's manufacturing listed companies based on the C-D function" (In Chinese), Harbin Institute of Technology.

Harris, R. D. F. and Tzavalis, E. (1999) "Inference for unit roots in dynamic panels where the time dimension is fixed" Journal of Econometrics, vol. 91, pp.201-226.

Hou, Z. D. (2010), "Empirical research on the impact of cultural industry development on economic growth" (In Chinese), Northeastern University of Finance and Economics. Levin, A.; Lin, C.F. and Chu, C.S.J. (2002), "Unit root tests in panel data: Asymptotic and finite-sample properties", Journal of Econometrics, vol. 108: pp. 1-24.

Liu, Y. C. (2014) "Empirical study on the impact of demographic change on economic growth in China" (In Chinese), Capital University of Economics and Business.

Subhalaxmi, M. \& Padmaja, M. (2011), “Composition of Public Expenditure on Health and Economic Growth: A Cointegration Analysis and Causality Testing”, IUP Journal of Public Finance, vol. 9, no. 2, pp.30-43.

Pesaran, M. H. (2004), "General diagnostic tests for cross section dependence in panels”, Cambridge Working Papers in Economics, University of Cambridge.

Razmi, M. J., Ahmadi, F. (2015), "The Effect of Health Expenditure on Economic Growth in Four Very High, High, Medium and Low Human Development Countries", Proceedings of the Multidisciplinary Academic Conference., pp.1-22.

Sun, H \& Jiang, X. K. (2014), Research on the impact of scientific and technological talents on regional economic development -- based on comparative analysis of data in 
east, middle and west regions (In Chinese). Guangdong social sciences, vol.2, pp.1521.

Jon, S., Yan F. Mestre-Ferrandiz, J., Pistollato, M, Jon Hafner, M., Burridge, P., Grant, J. (2016), "Quantifying the economic impact of government and charity funding of medical research on private research and development funding in the United Kingdom". BMC Medicine. vol. 14, no.2, pp.1-23.

Yang, H. \& Wang, F. H. (2015), "Discussion on the influence factors of Sichuan economic growth based on the Krongran function" (In Chinese), Times Finance, vol.15. 